\title{
MicroRNA-128-b regulates epidermal growth factor receptor expression in non-small cell lung cancer
}

\author{
LING $\mathrm{LI}^{1}$ and DONGQING WANG ${ }^{2}$ \\ ${ }^{1}$ Department of Oncology, Xintai People's Hospital, Xintai, Shandong 271200; \\ ${ }^{2}$ Department of Radiation Oncology, Shandong Tumor Hospital, Jinan, Shandong 250117, P.R. China
}

Received November 1, 2017; Accepted June 7, 2018

DOI: $10.3892 / \mathrm{mmr} .2019 .10731$

\begin{abstract}
The expression of epidermal growth factor receptor (EGFR) is regulated by microRNA (miRNA)-128-b in non-small cell lung cancer (NSCLC); however, the association between miRNA-128-b expression and EGFR expression has not been determined in vivo. The expression of miRNA-128-b was detected by reverse transcription (RT)-quantitative polymerase chain reaction (PCR); semi-quantitative RT-PCR was used to detect EGFR mRNA expression; immunostaining was used to detect EGFR protein expression. The results revealed that expression of miR28b in cancer tissues was decreased compared with normal tissues, and the expression of EGFR mRNA in cancer tissues was increased compared with normal tissues. Immunohistochemistry analysis revealed that the normal tissues did not express EGFR protein, and the positive expression rate of EGFR in cancer tissues was $60 \%$. Furthermore, the relative expression levels of miRNA-128-b were demonstrated to be correlated with EGFR mRNA and protein expression levels. In addition, the results revealed that miRNA-128-b regulated EGFR expression in NSCLC cells. In conclusion, the results of the present study suggested that miRNA-128-b may regulate the expression of EGFR in NSCLC cells, and that optimizing targeted therapy is conducive to the development of novel therapeutic strategies for the treatment of patients with lung cancer.
\end{abstract}

\section{Introduction}

Lung cancer is one of the primary causes of cancer mortality worldwide (1). Non-small cell lung cancer (NSCLC) accounts for $\sim 85 \%$ of lung cancer cases, of which $75 \%$ exhibit distant

Correspondence to: Professor Dongqing Wang, Department of Radiation Oncology, Shandong Tumor Hospital, 440 Jiyan Road, Jinan, Shandong 250117, P.R. China

E-mail:wdqlove2009@sina.com

Dr Ling Li, Department of Oncology, Xintai People's Hospital, 1329 Xinfu Road, Xintai, Shandong 271200, P.R. China

E-mail: lilingyx1@126.com

Key words: microRNA-128-b, epidermal growth factor receptor, non-small cell lung cancer metastases at diagnosis $(2,3)$. Since the introduction of numerous novel chemotherapy drugs, chemotherapy has been reported to significantly improve survival (4) however, chemotherapeutic toxicity has been detected in large numbers of patients (5).

Monoclonal antibodies and small molecule receptor tyrosine kinase inhibitors (TKIs) are two targeted drugs commonly used for treating patients with advanced NSCLC (6). Previous studies have revealed that epidermal growth factor receptor (EGFR)-TKIs are an effective treatment strategy that has a beneficial effect on tumors with EGFR gene mutations $(6,7)$. Furthermore, an increase in EGFR gene copy numbers has been demonstrated to be associated with improved survival prognosis for patients treated with TKI (8). In addition, 20-40\% of patients with NSCLC have concurrent mutations and gene amplification $(9,10)$. Recent studies have also demonstrated that some TKI-effective patients have no significant EGFR genetic changes (11). For TKIs, there are no clear patient selection criteria. In addition to mutation and genetic amplification, there may be other effects of targeted drug mechanisms (12)

MicroRNAs (miRNAs/miRs) are a class of mature small non-coding RNAs, varying between 22 and 25 nucleotides in length, that regulate gene expression at the post-transcriptional level by promoting degradation of target mRNAs or inhibition of protein synthesis $(12,13)$. Dysregulated miRNA expression has been demonstrated to be associated with numerous tumor types, thus suggesting that certain miRNAs can function as oncogenes or tumor suppressor genes (13). EGFR may be a miRNA128-b target gene, and it has been demonstrated that in NSCLC cells there is loss of heterozygosity in miRNA128-b, which is associated with EGFR-TKIs curative efficacy (14). However, the effect of miRNA-128-b on the regulation of EGFR expression in NSCLC remains unclear.

The present study aimed to investigate miRNA-128-b and EGFR expression levels in NSCLC cancer tissue compared with adjacent normal tissue, and investigate the association between the two factors and clinicopathological factors in patients with NSCLC, in order to determine the role of miRNA-128-b expression in lung cancer and the regulation of EGFR expression.

\section{Materials and methods}

Clinical data. Between March and August 2014, tissue specimens (cancer tissue and normal adjacent tissue) were collected 
following surgical treatment of 42 patients with NSCLC in Shandong Tumor Hospital (Jinan, China). Patients had not previously received any other preoperative radiotherapy and chemotherapy therapies. Following collection, tissue specimens were stored at $-80^{\circ} \mathrm{C}$ prior to subsequent analysis. The diagnosis and classification of these patients were performed by a professional pathologist, and later verified by subsequent morphological and immunohistochemistry analyses. Patients were staged according to the TNM system (15). The present study was granted ethical approval by the Shandong Tumor Hospital Ethics Committee, and written informed consent was obtained from patients. According to the alterations in miRNA-128-b expression in cancer tissues relative to normal tissues, tissue specimens were divided into the following three groups: The descending group, stable group and increasing group. The clinical data of patients included in the present study are presented in Table I.

Cell culture. Lung adenocarcinoma cell line A549 was obtained from the American Type Culture Collection (Manassas, VA, USA), cultured in RPMI containing 10\% fetal bovine serum (Hyclone; GE Healthcare, Chicago, IL, USA) at $37^{\circ} \mathrm{C}$, and subsequently maintained in a $5 \% \mathrm{CO}_{2}$ humidification incubator.

miRNA transfection. Cells (1.0-1.5 $\left.\times 10^{5}\right)$ were seeded into 6-well plates and after $24 \mathrm{~h}$ miRNA molecules (miRNA-128-b, 5'-UCA CAGUGAACCGGUCUCUUU-3'; miRNA-128-b inhibitor, 5'-AAAGAGACCGGUUCACUGUGA-3'; mimics NC, 5'-UUG UACUACACAAAAGUACUG-3'; inhibitor NC, 5'-CAG UACUUUUGUGUAGUACAA-3'; Guangzhou RiboBio, Co., Ltd., Guangzhou, China) were transfected into cells using Lipofectamine 2000 (Invitrogen; Thermo Fisher Scientific, Inc.), and the final plasmid concentration was $150 \mathrm{nM}$. Cells were collected $24 \mathrm{~h}$ post-transfection for subsequent RNA extraction and drug sensitivity analysis, and $48 \mathrm{~h}$ post-transfection for immunostaining analyses.

RNA extraction. Total RNA extraction was performed using TRIzol reagent (Invitrogen; Thermo Fisher Scientific, Inc., Waltham, MA, USA), and isolated RNA samples were then treated with DNase (2 U/ $\mu$ g; Promega Corporation, Madison, WI, USA).

Reverse transcription (RT)-quantitative polymerase chain reaction ( $q P C R)$ analysis of miRNA-128-b. A mirVana Quantitative RT-PCR miRNA kit (Ambion; Thermo Fisher Scientific, Inc.) was used to perform RT $\left(44^{\circ} \mathrm{C}\right.$ for $1 \mathrm{~h}$ and $92^{\circ} \mathrm{C}$ for $10 \mathrm{~min}$ ) according to the manufacturer's protocol. Briefly, total RNA (200 ng) was added to specific RT primers to synthesize complementary (c)DNA. The qPCR reaction consisted of the initial denaturation at $95^{\circ} \mathrm{C}$ for $10 \mathrm{~min}$, followed by 40 cycles for $15 \mathrm{sec}$ at $95^{\circ} \mathrm{C}$ and $1 \mathrm{~min}$ at $60^{\circ} \mathrm{C}$. The expression of miR128-b relative to RNA, U6 small nuclear 1 (RNU6B) was calculated using the $2^{-\Delta \Delta C q}$ method (16). All assays were performed in triplicate. Primer sequences were as follows: miRNA-128-b, forward, 5'-CGC GCTCACAGTGAACCG-3, reverse, 5'-GTGCAGGGTCCG AGGT-3'; and RNU6B, forward, 5'-CTCGCTTCGGCAGCA CA-3' and reverse, 5'-AACGCTTCACGAATTTGCGT-3'.
Semi-quantitative $R T$-PCR. RT was performed using ProtoScript ${ }^{\circledR}$ cDNA single-stranded synthesis kit (New England Biolabs, Inc., Ipswich, MA, USA), according to the manufacturer's protocol; PCR amplification was performed using Platinum Blue PCR SuperMix reagent (Invitrogen; Thermo Fisher Scientific, Inc.). Initial denaturation was performed at $94^{\circ} \mathrm{C}$ for 2 min followed by 40 cycles of $94^{\circ} \mathrm{C}$ for $20 \mathrm{sec}$ and $56^{\circ} \mathrm{C}$ for $55 \mathrm{sec}$; and a final extension step for $1 \mathrm{~min}$ at $72^{\circ} \mathrm{C}$. mRNA primer sequences used were as follows: EGFR forward, 5'-ATGCTCCCACCAC-3' and reverse, 5'-CCCTTC GCACTTCTTACAC-3'; and $\beta$-actin forward, 5'-ATGATG ATATCGCCGCGCT-3' and reverse, 5'-TGGGTCATCTTC TCGCGGTT-3'. The amplified product was analyzed on a $1.25 \%$ agarose gel, and EGFR mRNA expression was determined by grayscale scanning of the agarose gel containing ethidium bromide. Expression levels were calculated relative to $\beta$-actin expression. Data were semi-quantified using LightCycler analysis software v1.50 (Roche Diagnostics, Mannheim, Germany). All experiments were performed in triplicate.

EGFR immunohistochemistry (IHC) analysis. IHC was performed to investigate the expression of EGFR protein. After blocking the non-specific protein-binding sites with $20 \%$ goat serum (OriGene Technologies, Inc., Beijing, China) for $20 \mathrm{~min}$ at room temperature, anti-EGFR antibody staining (1:1,000; cat. no. PA1-1110; Zymed; Thermo Fisher Scientific, Inc.) was performed on A549 cells that were fixed with $4 \%$ paraformaldehyde at room temperature for $15 \mathrm{~min}$ and tissue sections obtained from patients that were fixed with $4 \%$ paraformaldehyde at $4^{\circ} \mathrm{C}$ (17). Subsequently, they were incubated with a goat anti-rabbit immunoglobulin-horseradish peroxidase secondary antibody (1:200; cat. no. TA130023; OriGene Technologies, Inc.) at $37^{\circ} \mathrm{C}$ for $30 \mathrm{~min}$. Tissue sections were classified as follows: $0,<10 \%$ positive cells; $1,10 \%$ positive cells; $2,11-50 \%$ positive cells; $3,>50 \%$ positive cells. The number of positive cells per field of view (0-100\%) and staining intensity (0, negative; 1 weak positive; 2 , medium positive; 3 , strong positive) of EGFR was determined (18). Images were captured using an IX71-SIF microscope (Olympus Corporation, Tokyo, Japan) at x 200 magnification. Two independent observers blinded to tissue status determined staining intensities in cell cytoplasm. Image-Pro Plus software (Media Cybernetics, Inc., Rockville, MD, USA) was used to quantify the mean densities of the expression intensities of EGFR, as previously described (18). Immunohistochemical positive staining in the cytoplasm was assessed, and two observers blinded to tissue status evaluated positive staining of each tissue core. An average of five images per tissue core was used for quantitative analysis.

Statistical analysis. All experiments were repeated three times and the data are presented as the mean \pm standard deviation. Statistical significant differences were determined by one-way analysis of variance followed by Fisher's least significant difference post-hoc test. Qualitative data were correlated using the Pearson correlation. Rates were compared using the $\chi^{2}$ test. Statistical analysis was performed using SPSS 19.0 software (IBM Corp., Armonk, NY, USA). P<0.05 was considered to indicate a statistically significant difference. 
Table I. Clinical information of patients and microRNA-128-b expression levels in cancerous and normal tissue.

\begin{tabular}{|c|c|c|c|c|c|}
\hline \multirow[b]{2}{*}{ Variable } & \multicolumn{3}{|c|}{ miRNA-128-b relative expression } & \multirow[b]{2}{*}{ Percentage $(\%)$} & \multirow[b]{2}{*}{ P-value } \\
\hline & $\mathrm{D}$ & $\mathrm{S}$ & $\mathrm{I}$ & & \\
\hline Sex & & & & & 0.89 \\
\hline Male & 23 & 5 & 6 & 0.81 & \\
\hline Female & 5 & 1 & 2 & 0.19 & \\
\hline Age (years) & & & & & 0.28 \\
\hline$<60$ & 16 & 3 & 2 & 0.50 & \\
\hline$\geq 60$ & 12 & 3 & 6 & 0.50 & \\
\hline Smoking & & & & & 0.9 \\
\hline No & 12 & 2 & 3 & 0.40 & \\
\hline Yes & 16 & 4 & 5 & 0.60 & \\
\hline Drinking & & & & & 0.17 \\
\hline No & 20 & 2 & 6 & 0.67 & \\
\hline Yes & 8 & 4 & 2 & 0.33 & \\
\hline TNM stage & & & & & 0.72 \\
\hline I & 9 & 2 & 1 & 0.29 & \\
\hline II & 5 & 2 & 2 & 0.21 & \\
\hline III & 14 & 2 & 5 & 0.50 & \\
\hline Pathological type & & & & & 0.9 \\
\hline Adenocarcinoma & 10 & 3 & 3 & 0.38 & \\
\hline Squamous & 11 & 2 & 4 & 0.40 & \\
\hline Others & 7 & 1 & 1 & 0.21 & \\
\hline Histology grade & & & & & 0.38 \\
\hline Low & 3 & 1 & 3 & 0.17 & \\
\hline Medium & 20 & 4 & 5 & 0.69 & \\
\hline High & 5 & 1 & 0 & 0.14 & \\
\hline EGFR mRNA & & & & & $<0.01$ \\
\hline $\mathrm{D}$ & 3 & 2 & 8 & 0.31 & \\
\hline I & 25 & 4 & 0 & 0.69 & \\
\hline EGFR protein expression & & & & & 0.03 \\
\hline Positive & 8 & 5 & 5 & 0.60 & \\
\hline Negative & 11 & 0 & 1 & 0.40 & \\
\hline
\end{tabular}

$\mathrm{D}$, decreased in tumor relative to normal tissue; S, stable; I, increased in tumor relative to normal tissue. miRNA, microRNA; IHC, immunohistochemistry; EGFR, epidermal growth factor receptor.

\section{Results}

miRNA-128-b expression in tissues. RT-qPCR was performed to detect the expression of miRNA-128-b in the cancerous tissues and adjacent normal tissues of 42 patients, and the results revealed that expression was not detected in 16 cancerous tissues or in 8 adjacent normal tissues. In 6 patients, miR-128-b expression was not detected in either cancerous or adjacent tissues (Fig. 1). The expression of miRNA 128 -b in 28 cases $(66.7 \%)$ of 42 cases was suppressed compared with normal tissues [tumor tissue (T): Normal tissue $(\mathrm{N})<1$ ]. The mean value of miRNA $128-\mathrm{b}$ expression in cancer tissues was $0.2 \pm 0.08$, and the mean value of miRNA 128 -b expression in normal tissues was $0.7 \pm 0.16(\mathrm{P}=0.04)$.
Association between miRNA-128-b expression and clinical pathological factors. Relative expression levels of miRNA128-b was revealed to be significantly associated with differences in EGFR mRNA expression and EGFR protein expression. However, no significant differences in miRNA 128-b expression regarding differences in sex, age, pathological type, operation stage and degree of differentiation were determined (Table I).

EGFR mRNA expression in tissues. RT-PCR was performed to detect EGFR mRNA expression in the cancer tissues and normal tissues of 42 patients (Fig. 2). The results revealed that EGFR mRNA expression was enhanced in cancer tissue compared with normal tissue in $69 \%$ of patients $(\mathrm{T}: \mathrm{N} \geq 1.0)$. The mean EGFR mRNA expression was revealed to be 


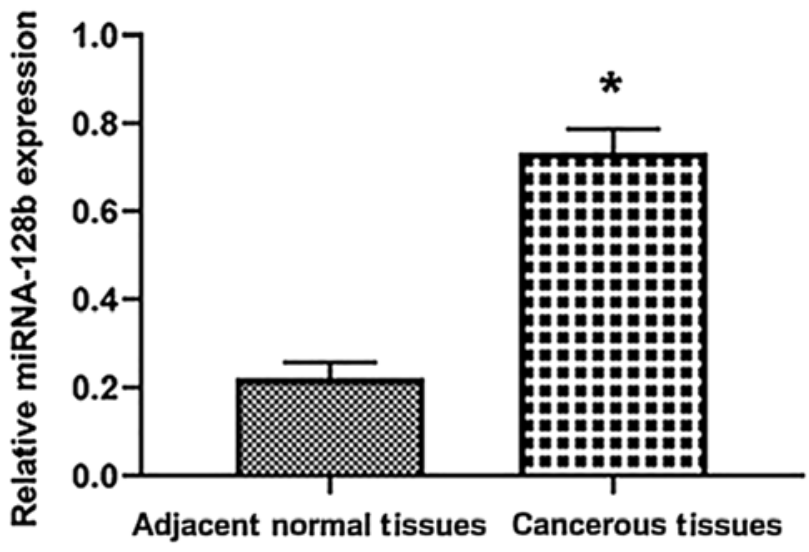

Figure 1. miRNA-128-b expression levels in tissues obtained from patients with NSCLC. Reverse transcription-quantitative polymerase chain reaction was performed to determine the expression levels of miRNA-128-b in cancerous tissues and adjacent normal tissues obtained from 42 patients with NSCLC. The mean expression levels of miRNA-128-b in cancerous and normal tissues were $0.02 \pm 0.08$ and $0.07 \pm 0.16$, respectively $(\mathrm{P}=0.04){ }^{*} \mathrm{P}<0.05$. NSCLC, non-small cell lung cancer; miRNA, microRNA

$0.57 \pm 0.16$ in the cancer tissue, and $0.48 \pm 0.16$ in normal tissue $(\mathrm{P}=0.02)$.

EGFR protein expression in tissue. IHC staining of EGFR protein was performed in 30 of the 42 tissue samples. EGFR protein staining was revealed to be negative (Fig. 3A) or weakly positive (Fig. 3B) in normal tissue samples, in which staining was limited to basal levels ( $<10 \%$ positive cells). EGFR protein expression in cancer tissues was revealed to be increased compared with normal tissue samples. When the number of positive cells was $10 \%$ (1), the sample was considered positive for EGFR protein expression; EGFR positive expression was detected in $18(60 \%)$ cancer tissues (Fig. 3C). When the number of positive cells was $>10 \%$ (2 and 3), the sample was considered to have high EGFR protein expression; EGFR protein was highly expressed in 10 patients (Fig. 3D and E). As demonstrated in Fig. 4, EGFR protein expression was associated with TNM stage $(\mathrm{P}<0.05$ TNM stage II or III vs. TNM stage I).

Association between the expression of miRNA-128-b and the expression of EGFR in lung cancer tissues. Pearson correlation analysis demonstrated that there were significant negative correlations between the relative expression of miRNA128-b and both EGFR mRNA relative expression and EGFR protein expression $(r=-0.69, \mathrm{P}=0.02$, Fig. $5 \mathrm{~A} ; \mathrm{r}=-0.43$, $\mathrm{P}=0.02$, Fig. 5B).

miRNA-128-b regulates EGFR expression in lung cancer cell lines. miRNA-128-b mimics and inhibitors were transfected into A549 cells expressing EGFR protein to investigate the effect of miRNA-128-b on the regulation of EGFR expression. The expression of miRNA-128-b in cells transfected with mimics significantly increased compared with the control group, and the inhibitor group exhibited significantly decreased miRNA-128-b expression levels compared with the control group. Compared with the control group, EGFR mRNA expression was significantly

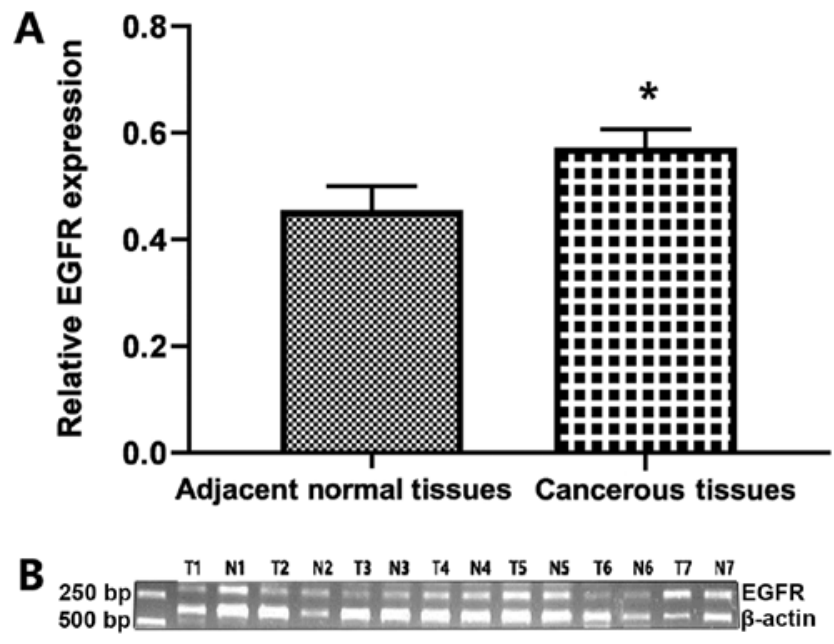

Figure 2. EGFR mRNA expression levels in tissues obtained from patients with NSCLC. (A and B) Reverse transcription-semi-quantitative polymerase chain reaction was performed to investigate EGFR mRNA expression levels in cancerous and normal tissues obtained from 42 patients with NSCLC. The mean EGFR mRNA expression levels in cancerous and normal tissues were $0.57 \pm 0.16$ and $0.48 \pm 0.16$, respectively $\left({ }^{*} \mathrm{P}=0.02\right)$. EGFR, epidermal growth factor receptor; $\mathrm{T}$, tumor tissue; $\mathrm{N}$, normal tissue; NSCLC, non-small cell lung cancer; bp, base pairs.

suppressed in cells transfected with miRNA-128-b mimics compared with control cells; whereas EGFR mRNA expression was significantly increased the inhibitor-treated cells compared with control cells $(\mathrm{P}<0.05$; Fig. 6A and $\mathrm{B})$. In addition, Fig. 7 presented the results of immunohistochemistry analysis following transfection with miRNA-128-b mimics or inhibitors. The expression of EGFR protein in cells treated with miRNA-128-b inhibitors was significantly upregulated compared with control cells; whereas EGFR protein expression was significantly downregulated in cells treated with miRNA-128-b mimics compared with control cells $(\mathrm{P}<0.05$ vs. control; Fig. $7 \mathrm{~B})$.

\section{Discussion}

Over the past 40 years, the understanding of potential cellular or genetic changes associated with lung cancer has developed. The EGFR signal transduction pathway has been suggested to represent a therapeutic target, leading to the development of small-molecule TKIs. It has been reported that EGFR-TKIs are only effective in 10-30\% of patients with chemotherapy-refractory NSCLC (19-21), and so the identification of novel regulatory molecules may optimize targeting therapy for lung cancer.

miRNAs are a class of small molecule non-coding RNAs, and a considerable number of microRNAs are located in tumor-associated gene loci or fragile sites, thus suggesting that miRNAs may be involved in tumorigenesis. The deletion of chromosome $3 p$ allele is common in the early stages of lung cancer, which results in dysregulation of EGFR expression (18). miRNA-128-b is located on chromosome 3p22, and regulates EGFR expression in NSCLC cells via binding with the 3' untranslated region (3'UTR) (18).

To the best of our knowledge, the association between miRNA-128-b expression and EGFR expression has not been reported in NSCLC, the previous study conducted a systematic 
A

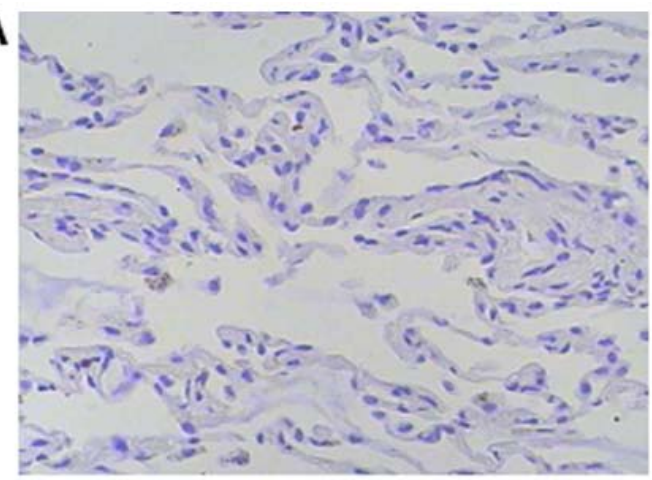

C

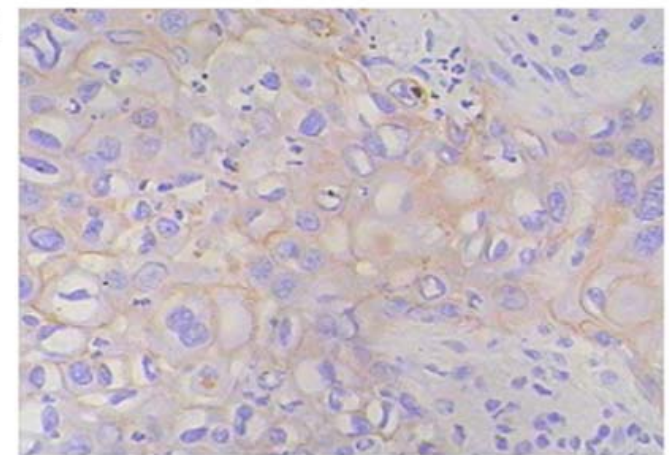

B

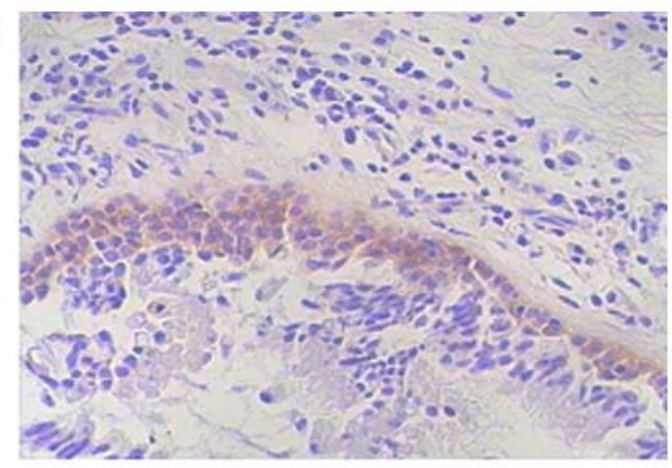

D

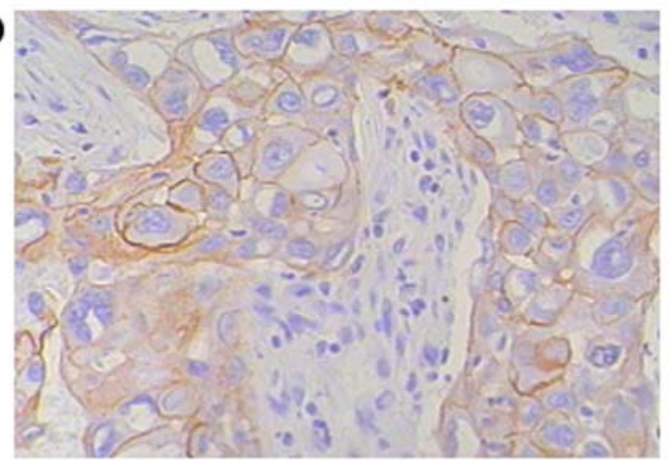

$\mathbf{E}$

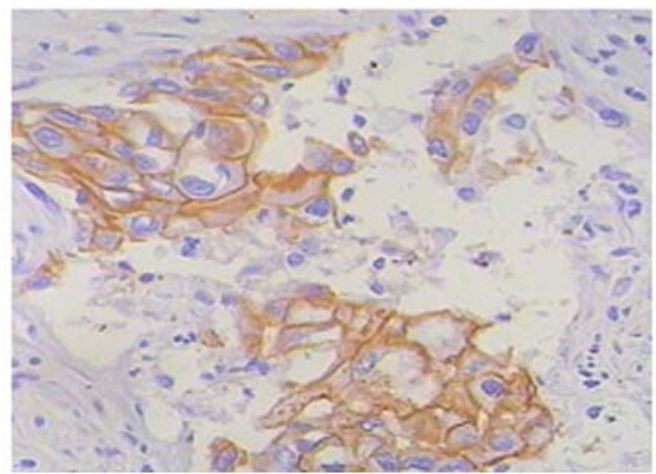

Figure 3. Immunohistochemistry staining was performed to investigate EGFR protein expression in tissues obtained from 30 of the 42 tissue samples patients with non-small cell lung cancer (magnification, x200). (A) Negative and (B) weakly positive EGFR protein expression in normal tissue. (C) Positive EGFR protein expression $(10 \%, 1)$ was detected in cancer tissues. (D and E) High EGFR protein expression $(>10 \%, 2$ and 3 ) was highly detected in 10 patients with non-small cell lung cancer. EGFR protein expression was associated with stages $(\mathrm{P}=0.04)$. EGFR, epidermal growth factor receptor.

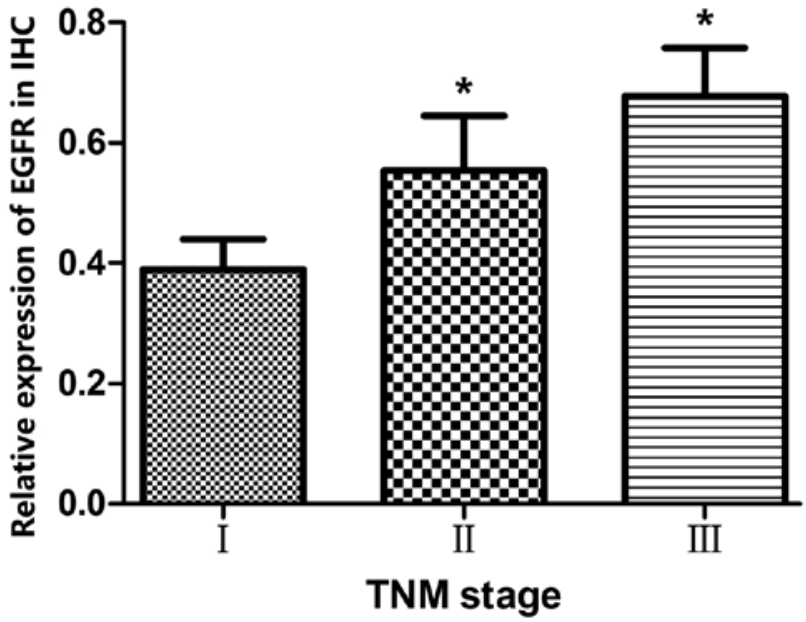

Figure 4. Quantitative analysis of IHC staining results revealed that EGFR protein expression was revealed to increase in a TNM stage-dependent manner. ${ }^{*} \mathrm{P}<0.05$ vs. TNM stage I. EGFR, epidermal growth factor receptor; IHC, immunohistochemistry. analysis (10). EGFR may be a miRNA-128-b target gene, and it has been demonstrated that in NSCLC cells there is loss of heterozygosity in miRNA-128-b, which is associated with EGFR-TKIs curative efficacy $(20,21)$. Firstly, differences in miRNA-128-b expression and EGFR expression between cancerous tissue and normal tissue were compared. miRNA-128-b expression was occasionally not detected in tumor tissues and was revealed to be decreased in cancerous tissue compared with normal tissue. The results demonstrated that EGFR mRNA was expressed in all samples; however, the expression of EGFR mRNA was revealed to be enhanced in cancerous tissue compared with normal tissue. The difference of the same mRNA expression between normal tissues and cancerous tissues may be a result of the heterogeneity of the expression patterns in different tissue types or due to the biological behavior of the tumor. IHC results demonstrated that the expression of EGFR in normal tissues was negative or weakly positive, whereas the expression of EGFR protein in cancerous tissues was increased compared with normal 

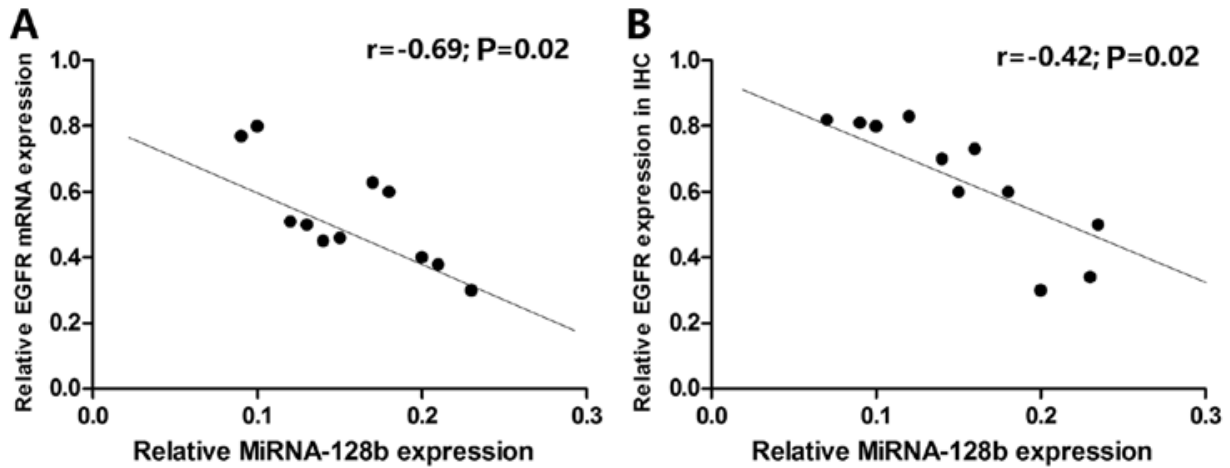

Figure 5. Association between the expression levels of miRNA-128-b and the expression of EGFR in lung cancer tissues. Pearson correlation analysis demonstrated that there were a significant negative correlations between the relative expression levels of miRNA-128-b and (A) EGFR mRNA relative expression ( $\mathrm{r}=-0.69$; $\mathrm{P}=0.02)$ and $(\mathrm{B}) \mathrm{EGFR}$ protein expression ( $\mathrm{r}=-0.43 ; \mathrm{P}=0.02)$. EGFR, epidermal growth factor receptor; miRNA, microRNA; IHC, immunohistochemistry.
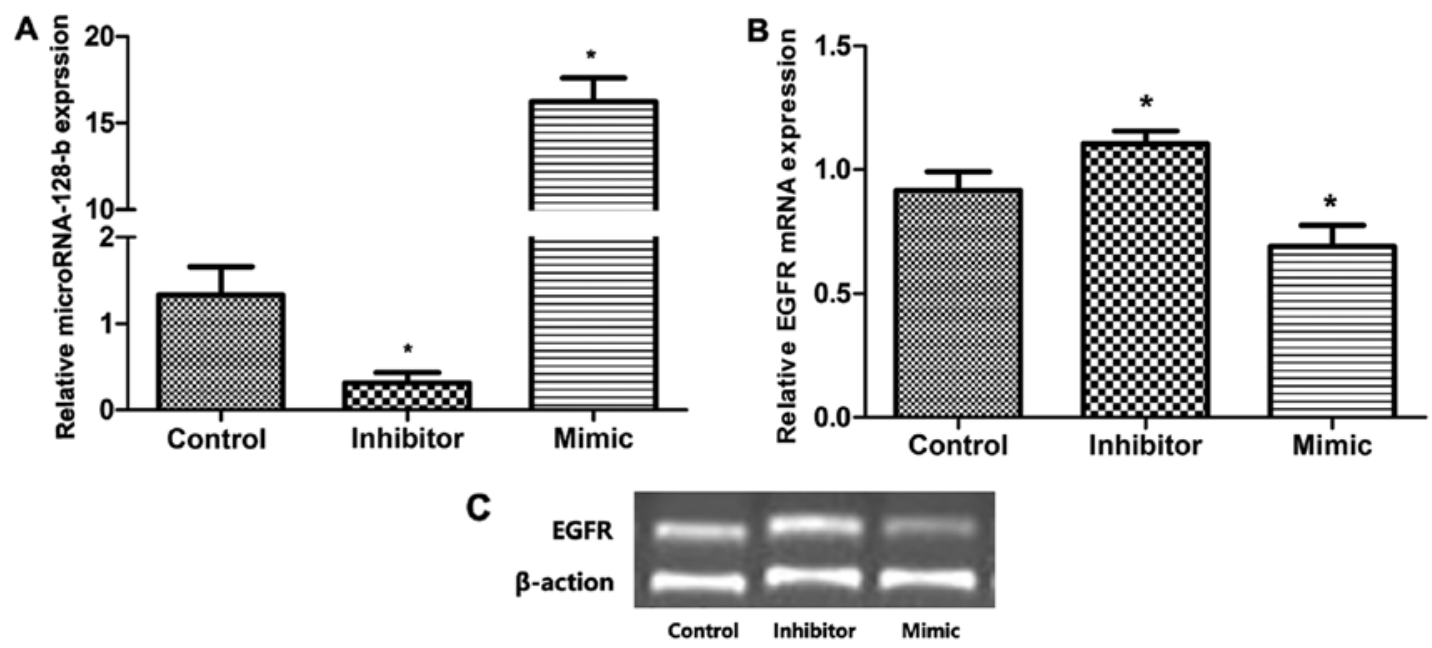

Figure 6. miRNA-128-b regulated EGFR expression in lung cancer cell lines. (A) The relative expression of miRNA-128-b in the mimic group was enhanced compared with the control group, and the relative expression of miRNA-128-b in the inhibitor group was significantly decreased compared with the control group. (B) The relative expression of EGFR mRNA in the mimic group was significantly suppressed compared with the control group, and the relative expression of EGFR mRNA in the inhibitor group was significantly increased compared with the control group. (C) Agarose gel representing the expression levels of miRNA-128-b and EGFR mRNA following transfection in A549 cells. "P<0.05 vs. control. EGFR, epidermal growth factor receptor; miRNA, microRNA.

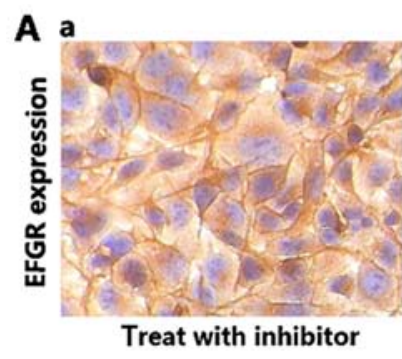

b

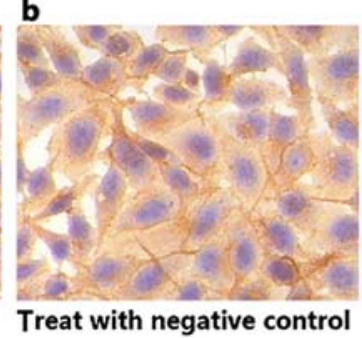

B

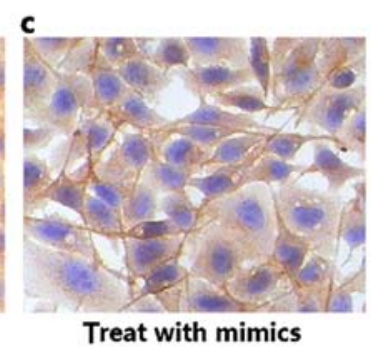

Treat with mimics

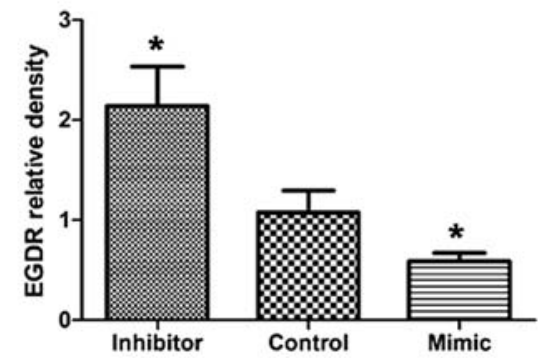

Figure 7. Expression of EGFR protein was detected by immunohistochemistry in A549 cells. (A) A549 cells were treated with miRNA 128-b inhibitors, negative controls and mimics. (B) The expression of EGFR protein in miRNA 128-b-treated cells was significantly upregulated compared with the control group, while EGFR protein expression was significantly downregulated in cells treated with mimics compared with the control group. "P<0.05 vs. control. EGFR, epidermal growth factor receptor; miRNA, microRNA. 
tissues. Consistent with a previous study (22), expression levels of EGFR protein were revealed to be increased in stage III NSCLC compared with earlier stages of NSCLC. It has been previously suggested that EGFR expression increases progressively in a stage-dependent manner in NSCLC (23). In addition, the correlation between miRNA128-b expression and EGFR expression was analyzed in cancerous tissues. Pearson correlation analysis demonstrated that there were significant negative correlations between the relative miRNA128-b expression and relative EGFR mRNA and protein expression

Previous studies have investigated the association between miRNA expression and mRNA expression in NSCLC tissues. Tumor suppressor candidate 2 (TUSC2) is a tumor suppressor gene and is located on chromosome 3p21. miRNA-93 and miRNA-197 bind to the TUSC2 3'UTR to negatively regulate its expression in NSCLC tissues (24). The results of the present study demonstrated that the relative expression of miRNA-128-b was negatively correlated with the relative expression of EGFR mRNA in cancerous tissue. In addition, the results revealed that miRNA-128-b expression was sometimes absent in the tumor compared with the normal tissue, and the relative expression of miRNA-128-b was decreased, unchanged and increased in three cases in cancer tissues, and was significantly correlated with EGFR protein expression.

Furthermore, the results of the present study suggested that miRNA-128-b regulates EGFR expression in NSCLC cells. A549 cells expressing EGFR and miRNA-128-b were investigated, and EGFR expression was revealed to be downregulated following transfection with mimics, whereas EGFR expression was upregulated following treatment with inhibitors, and drug sensitivity was subsequently increased. Similarly, H157 cells are EGFR-expressing cell lines, and a previous study revealed that treatment with miRNA-128-b inhibitors upregulated EGFR protein expression, while EGFR protein expression was downregulated following miRNA-128-b mimic treatment (18).

The results of present study suggested that miRNA-128-b expression and EGFR expression were differentially expressed in cancer tissues compared with normal tissues, and the relative expression of miRNA-128-b was negatively correlated with EGFR mRNA and EGFR protein expression levels in cancerous tissues. miRNA-128-b regulated EGFR expression in NSCLC cells, thereby affecting the drug sensitivity of cells. These results suggested that miRNA-128-b may exhibit an inhibitory role in lung cancer. However, the efficacy of existing anti-EGFR drugs for the treatment of lung cancer is limited, and thus the development of novel therapeutic strategies is necessary to successfully suppress signal transduction and EGFR expression. Inhibition of signal transduction via EGFR-TKIs and inhibition of EGFR expression via miRNA-128-b may represent a novel therapeutic strategy for the treatment of patients with EGFR mutant-harboring NSCLC.

\section{Acknowledgements}

Not applicable.

\section{Funding}

The Natural Science Foundation of Shandong Province (grant no. Y2005C49) supported the present study.

\section{Availability of data and materials}

All data generated or analyzed during this study are included in this published article.

\section{Authors' contributions}

LL and DW conceived and designed the study. DW collected the data. LL performed the experiments, prepared the diagrams and drafted the manuscript. LL and DW reviewed and edited the manuscript. All authors read and approved the final manuscript.

\section{Ethics approval and consent to participate}

The present study was granted ethical approval by the Shandong Tumor Hospital Ethics Committee. Written informed consent was obtained from the patients.

\section{Patient consent for publication}

Written informed consent was obtained from the patients.

\section{Competing interests}

The authors declare that they have no competing interests.

\section{References}

1. Kligerman S and White C: Epidemiology of lung cancer in women: Risk factors, survival, and screening. AJR Am J Roentgenol 196: 287-295, 2011.

2. Yang JC, Kang JH, Mok T, Ahn MJ, Srimuninnimit V, Lin CC, Kim DW, Tsai CM, Barraclough H, Altug S, et al: First-line pemetrexed plus cisplatin followed by gefitinib maintenance therapy versus gefitinib monotherapy in East Asian patients with locally advanced or metastatic non-squamous non-small cell lung cancer: A randomised, phase 3 trial. Eur J Cancer 50: 2219-2230, 2014.

3. Brown T, Boland A, Bagust A, Oyee J, Hockenhull J, Dundar Y, Dickson R, Ramani VS and Proudlove C: Gefitinib for the first-line treatment of locally advanced or metastatic non-small cell lung cancer. Health Technol Assess 14 (Suppl):71-99, 2010.

4. Mendoza L: Targeted therapies in the treatment of advanced non-small-cell lung cancer: Update. Klin Onkol 22: 131-138, 2009.

5. Avery EJ, Kessinger A and Ganti AK: Therapeutic options for elderly patients with advanced non-small cell lung cancer. Cancer Treat Rev 35: 340-344, 2009.

6. Ahn HK, Choi YL, Han JH, Ahn YC, Kim K, Kim J, Shim YM, Um SW, Kim H, Kwon OJ, et al: Epidermal growth factor receptor mutation and treatment outcome of mediastinoscopic N2 positive non-small cell lung cancer patients treated with neoadjuvant chemoradiotherapy followed by surgery. Lung Cancer 79: 300-306, 2013.

7. Tanaka K, Hida T, Oya Y, Oguri T, Yoshida T, Shimizu J, Horio Y, Hata A, Kaji R, Fujita S, et al: EGFR mutation impact on definitive concurrent chemoradiation therapy for inoperable stage III adenocarcinoma. J Thorac Oncol 10: 1720-1725, 2015.

8. Dahabreh IJ, Linardou H, Kosmidis P, Bafaloukos D and Murray S: EGFR gene copy number as a predictive biomarker for patients receiving tyrosine kinase inhibitor treatment: A systematic review and meta-analysis in non-small-cell lung cancer. Ann Oncol 22: 545-552, 2011.

9. Fukuoka M, Wu YL, Thongprasert S, Sunpaweravong P, Leong SS, Sriuranpong V, Chao TY, Nakagawa K, Chu DT, Saijo N, et al: Biomarker analyses and final overall survival results from a phase III, randomized, open-label, first-line study of gefitinib versus carboplatin/paclitaxel in clinically selected patients with advanced non-small-cell lung cancer in Asia (IPASS). J Clin Oncol 29: 2866-2874, 2011. 
10. Murphy M and Stordal B: Erlotinib or gefitinib for the treatment of relapsed platinum pretreated non-small cell lung cancer and ovarian cancer: A systematic review. Drug Resist Updat 14: 177-190, 2011.

11. Pirker R: What is the best strategy for targeting EGF receptors in non-small-cell lung cancer. Future Oncol 11: 153-167, 2015.

12. Cheng Q, Yi B, Wang A and Jiang X: Exploring and exploiting the fundamental role of microRNAs in tumor pathogenesis. Oncol Targets Ther 6: 1675-1684, 2013.

13. Xia H and Hui KM: MicroRNAs involved in regulating epithelial-mesenchymal transition and cancer stem cells as molecular targets for cancer therapeutics. Cancer Gene Ther 19: 723-730, 2012.

14. Weiss GJ,Bemis LT,NakajimaE,Sugita M,Birks DK, Robinson WA, Varella-Garcia M, Bunn PA Jr, Haney J, Helfrich BA, et al: EGFR regulation by microRNA in lung cancer: Correlation with clinical response and survival to gefitinib and EGFR expression in cell lines. Ann Oncol 19: 1053-1059, 2008.

15. Chheang $\mathrm{S}$ and Brown K: Lung cancer staging: Clinical and radiologic perspectives 30: 99-113, 2013.

16. Yanaihara N, Caplen N, Bowman E, Seike M, Kumamoto K, Yi M, Stephens RM, Okamoto A, Yokota J, Tanaka T, et al: Unique microRNA molecular profiles in lung cancer diagnosis and prognosis. Cancer Cell 9: 189-198, 2006.

17. Wang W, Wen Q, Xu L, Xie G, Li J, Luo J, Chu S, Shi L, Huang D, Li J and Fan S: Activation of Akt/mTOR pathway is associated with poor prognosis of nasopharyngeal carcinoma. PLoS One 9: e106098, 2014

18. Ling LI and Song LH: The role of MicroRNA in lung cancer. J Clin Oncol 36: 1377-1380, 2009 (In Chinese).

19. Zhao N, Zhang XC, Yan HH, Yang JJ and Wu YL: Efficacy of epidermal growth factor receptor inhibitors versus chemotherapy as second-line treatment in advanced non-small-cell lung cancer with wild-type EGFR: A meta-analysis of randomized controlled clinical trials. Lung Cancer 85: 66-73, 2014.
20. Wang S, Su X, Bai H, Zhao J, Duan J, An T, Zhuo M, Wang Z, Wu M, Li Z, et al: Identification of plasma microRNA profiles for primary resistance to EGFR-TKIs in advanced non-small cell lung cancer (NSCLC) patients with EGFR activating mutation. J Hematol Oncol 8: 127, 2015.

21. Duan X and Shi J: Advance in microRNAs and EGFR-TKIs secondary resistance research in non-small cell lung cancer. Zhongguo Fei Ai Za Zhi 17: 860-864, 2014 (In Chinese).

22. Aichler M, Motschmann M, Jütting U, Luber B, Becker K, Ott K, Lordick F, Langer R, Feith M, Siewert JR and Walch A: Epidermal growth factor receptor (EGFR) is an independent adverse prognostic factor in esophageal adenocarcinoma patients treated with cisplatin-based neoadjuvant chemotherapy. Oncotarget 5: 6620-6632, 2014.

23. Ludovini V,Bellezza G,PistolaL,BianconiF, Di Carlo L,Sidoni A, Semeraro A, Del Sordo R, Tofanetti FR, Mameli MG, et al: High coexpression of both insulin-like growth factor receptor-1 (IGFR-1) and epidermal growth factor receptor (EGFR) is associated with shorter disease-free survival in resected non-small-cell lung cancer patients. Ann Oncol 20: 842-849, 2009.

24. Du L, Schageman JJ, Subauste MC, Saber B, Hammond SM, Prudkin L, Wistuba II,JiL, Roth JA, Minna JD and Pertsemlidis A: miR-93, miR-98, and miR-197 regulate expression of tumor suppressor gene FUS1. Mol Cancer Res 7: 1234-1243, 2009.

c) (i) $\Theta$ This work is licensed under a Creative Commons Attribution-NonCommercial-NoDerivatives 4.0 International (CC BY-NC-ND 4.0) License. 